\title{
Long term quality of life after laparoscopic antireflux surgery for the elderly
}

\author{
Salvatore Tolone*, Giovanni Docimo, Gianmattia Del Genio, Luigi Brusciano, Ignazio Verde, Simona Gili, \\ Chiara Vitiello, Antonio D’Alessandro, Giuseppina Casalino, Francesco Saverio Lucido, Nicola Leone, Raffaele Pirozzi, \\ Roberto Ruggiero, Ludovico Docimo
}

From 26th National Congress of the Italian Society of Geriatric Surgery

Naples, Italy. 19-22 June 2013

\begin{abstract}
Background: Studies have previously shown laparoscopic antireflux surgery is a safe and effective treatment for GERD even in elderly patients. The aim of the current study was to evaluate patients receiving laparoscopic antireflux surgery before and after 65 years of age and to assess their surgical outcomes and improvements in long term quality of life.
\end{abstract}

Methods: Patients were given a standardized symptoms questionnaire and the Short-Form 36 Health Survey for quality-of-life evaluation before and after laparoscopic total fundoplication.

Results: Forty-nine patients older than 65 years of age were defined as the elderly group (EG) whereas the remaining 262 younger than 65 years of age were defined as the young group (YG).

There were 114 (36.6\%) patients who filled out the SF36 questionnaire (98 in the younger group, rate: 37.4\%; 16 in the elderly group, rate: $32.6 \%)$ pre- and post-operatively. There was no significant difference between the two age groups regarding preoperative PCS ( $45.6 \pm 7.8$ in YG vs. $44.2 \pm 8.2$ in EG; $P=0.51$ ) and MCS ( $48.1 \pm 10.7$ in YG vs. $46.9 \pm 9.2$ in $E G ; P=0.67)$. There was no significant difference between the two age groups regarding postoperative PCS $(49.8 \pm 11.9$ in $Y G$ and $48.2 \pm 9.5$ in $E G ; P=0.61$ and MCS (48.4 \pm 10.7 in YG vs. $50.1 \pm 6.9$ in $E G ; P=0.54)$.

Conclusions: In conclusion, laparoscopic total fundoplication is a safe and effective surgical treatment for gastroesophageal reflux disease generally warranting low morbidity and mortality rates and a significant improvement of symptoms comparable. An improved long-term quality of life is warranted even in the elderly.

\section{Background}

Gastroesophageal reflux disease is a frequent chronic disease related to retrograde flow of gastroduodenal contents into the esophagus [1]. As long-term therapeutic strategies for chronic gastro-esophageal reflux disease (GERD), surgery and Proton-pump inhibitors are effective and well tolerated, with antireflux surgery being superior in controlling overall disease manifestations [2]. Only 20 years have passed since the introduction of the first laparoscopic cholecystectomy and its general

\footnotetext{
* Correspondence: salvatore.tolone@unina2.it

Division of General and Bariatric Surgery, Department of Surgery, Second University of Naples, Via S. Pansini 5, 80131, Naples, Italy
}

acceptance as the standard treatment for patients with benign and malignant disease [3-7]. Since then, a great number of different surgical procedures has been carried out via laparoscopy [8-11] Laparoscopic surgery for GERD carries significant advantages in terms of lower overall morbidity, shorter postoperative hospital stay, and faster return to normal physical activity [12]. The measurement of quality of life ( QoL) is of paramount importance when attempting to compare outcomes after treatments, because neither questioning the patient about symptoms nor the assessment of objective instrumental testing seem to adequately provide an adequate assessment of patients subjective wellbeing [13].
C Biomed Central

(c) 2013 Tolone et al; licensee BioMed Central Ltd. This is an open access article distributed under the terms of the Creative Commons Attribution License (http://creativecommons.org/licenses/by/2.0), which permits unrestricted use, distribution, and reproduction in any medium, provided the original work is properly cited. 
Studies have previously shown laparoscopic antireflux surgery is a safe and effective treatment for GERD even in elderly patients, warranting low morbidity and mortality rates and a significant improvement of symptoms comparable to younger patients $[14,15]$.

The aim of the current study was to evaluate patients receiving laparoscopic antireflux surgery before and after 65 years of age and to assess their surgical outcomes and improvements in long term quality of life.

\section{Methods}

A prospective electronic database of all patients admitted for GERD in our university medical center (Division of General Surgery, Second University of Naples, Naples, Italy), was reviewed. Demographic data were obtained at the time of first visit. Patients older than 65 years of age were defined as the elderly group (EG) whereas the remaining as the young group (YG).

The study protocol was approved previously by the Ethical Committee of the Second University of Naples. All patients and controls were Caucasians from Italy.

Patients having typical or atypical symptoms for at least 6 months and requiring daily medical therapy for symptom control were offered the alternative of continuing with medical therapy or undergoing antireflux surgery. Patients who had undergone previous antireflux surgery or who required a concurrent abdominal procedure at the same time as fundoplication (eg, cholecystectomy), as well as patients with Barrett's esophagus, were excluded from this study.

All patients underwent a scheduled work-up that included upper- gastrointestinal endoscopy, barium meal radiograph examination, stationary esophageal manometry, 24-hour ambulatory $\mathrm{pH}$ monitoring and since available also 24 hours Combined Multichannel Intraluminal Impedance and $\mathrm{pH}$-monitoring (MII-pH) as well as Combined Multichannel Intraluminal Impedance and Esophageal Manometry (MII-EM) or High Resolution impedance Manometry (HRiM) [16].

After a brief interview and examination to assess for presence and severity of gastrointestinal symptoms and to make anthropometric measurements, all subjects completed a brief symptom assessment questionnaire. The questionnaire incorporated a visual analog scale (modified DeMeester Score) for heartburn, regurgitation and atypical symptoms [14].

Quality of life was evaluated using the Italian language Short-Form 36 (SF-36) $[17,18]$.

This is a generic measure of perceived health status, widely used in medical and health service research, that incorporates behavioral functioning, subjective well-being, and perception of health by assessing 8 health concepts: physical function, role-physical, bodily pain, general health, vitality, social function (SF), role emotional, and mental health. The Italian translation of this questionnaire has been validated previously using objective psychometric criteria.14 Scores range from 0 to 100, with higher scores indicating better functioning and well-being. Ware et al 15 developed Physical Component Summary (PCS) and Mental Component Summary (MCS) scores based on the SF-36 scales. The PCS is mostly the result of the following health concept: physical function, role-physical, and bodily pain. The MCS is mostly the result of the following health concept: SF, role-emotional, and mental health. Three of the scales (vitality, general health, and SF) have noteworthy correlations with both components. The 2 sets of summary scores have been proven to provide reliable evidence of medical well-being in the US general population; a 3-point difference in the scores is regarded as clinically important. All patients underwent a laparoscopic total fundoplication. An antibiotic prophylaxis was administered preoperatively [19].

The rate of complications and death events was recorded [20].

Briefly, patient is placed in a lithotomy position with legs abducted. Five trocars are placed as previously described. The gastric fundus is mobilized well, dissecting the fold of the peritoneal reflection and completely resecting the gastrophrenic ligament without dividing the short gastric vessels. After exposing the esophageal anterior wall and identifying the anterior vagal nerve, surgical dissection by ultrasonic dissection is accomplished [21-23].

The diaphragmatic crus is divided and the lower mediastinal and abdominal portion of the esophagus is mobilized. Taking care to avoid injury to the posterior vagal nerve, a wide retroesophageal space is created and the esophagus is retracted gently retracted to approximate the crura with 1 nonabsorbable stitch. Then a $360^{\circ}$ antireflux wrap is constructed by suturing 2 gastric hemivalves with 2 nonabsorbable stitches placed $20 \mathrm{~mm}$ apart. The suture does not include the esophageal wall, diaphragmatic pillars, or lesser gastric curve. Then, the endoscope is reinserted to check the morphologic aspect of the fundoplication. The use of hemostatic agents was employed when necessary [24].

When applicable, patients underwent protocols consistent with previous studies[25,26].

All patients were contacted by telephone or mail at least 1 year after laparoscopic total fundoplication and invited to came and answer the same questionnaires administered preoperatively. Satisfaction of the procedure and the will of undergoing the same operation after knowing its effects were defined as excellent outcome [27]. Statistical analysis was performed on the patients who completed the postoperative evaluation using SPSS for Windows (version 17.0; SPSS, Inc., Chicago, IL). Results were expressed as mean \pm SD unless otherwise 
indicated. Continuous variables were compared by the unpaired and paired Student ttest and dichotomic variables were compared by the chi-squared test and the McNemar test. The Wilcoxon signed-rank sum test was used to compare the preoperative and postoperative symptom severity score. The data were analyzed by Mann-Whitney $U$ tests to test for outcome differences between young and older patients. P value $<0.05$ was considered statistically significant.

\section{Results}

From September 2001 to December 2011, 311 consecutive patients, 127 male and 184 female, mean age 45.8 years (range 12-80) with GERD underwent laparoscopic Nissen- Rossetti fundoplication.

Forty-nine patients older than 65 years of age were defined as the elderly group (EG) whereas the remaining 262 younger than 65 years of age were defined as the young group (YG).

Demographics data and ASA score of the two groups are listed in Table 1.

All the interventions were completed via laparoscopic approach. Mean operative time was $53 \pm 12 \mathrm{~min}$ in YG and $64.6 \pm 17 \mathrm{~min}$ in EG. No mortality was observed in both groups. A major complication occurred in 4/262 patients (1.5\%), all among the YG. Blood loss was lower in YG group $(P=0.0001$. $)$ Mean postoperative hospital stay was longer in the EG group $(P=0.0001)$ (Table 2$)$. Normal activity resumed in $8.4 \pm 3.7$ days in YG and $12.1 \pm 7.5$ days in EG $(P=0.0001)$.

At the follow-up evaluation (mean, $48.1 \pm 12.4$ mo; range, 12-84 mo) antireflux surgery significantly diminished the symptom severity score of heartburn, epigastric pain, regurgitation, and respiratory symptoms in both groups $(P<0.05)$. Persisting postoperative dysphagia (DeMeester score 2-3) leading to $>15 \%$ of weight loss was observed in 10 (4\%) of 262 patients in YG and in $2(4 \%)$ of 49 patients. An excellent outcome was observed in $92 / 98$ (94\%) younger patients and in $15 / 16$ (93.7\%) elderly patients $(P=0.98)$.

\section{Quality of life}

There were 114 (36.6\%) patients who filled out the SF36 questionnaire (98 in the younger group, rate: $37.4 \% ; 16$ in the elderly group, rate: $32.6 \%)$ pre- and postoperatively.

Table 1 Demographics

\begin{tabular}{llll}
\hline & EG $(\mathbf{n}=\mathbf{4 9})$ & YG $(\mathbf{n}=\mathbf{2 6 2})$ & $\mathbf{p}$-value \\
\hline Age & $73.2 \pm 1.8$ & $49.2 \pm 3.5$ & 0.0001 \\
Gender(Male) & 13 & 73 & 0.88 \\
ASA score & $2.3 \pm 0.5$ & $2.4 \pm 0.6$ & 0.273 \\
BMI & $24.9 \pm 3.7$ & $24.7 \pm 3.3$ & 0.69 \\
\hline
\end{tabular}

Table 2 Surgical outcomes

\begin{tabular}{llll}
\hline & EG $(\mathbf{n}=\mathbf{4 9})$ & YG $(\mathbf{n}=\mathbf{2 6 2})$ & p-value \\
\hline OR time $(\mathrm{hr})^{*}$ & $64.6 \pm 17$ & $53.9 \pm 12$ & 0.0001 \\
EBL & $53 \pm 17$ & $34 \pm 13$ & 0.0001 \\
Complications & 0 & 4 & 0.38 \\
LOS(d) $\neq$ & $3.6 \pm 1.4$ & $2.8 \pm 1.3$ & 0.0001 \\
\hline
\end{tabular}

*OR, operative time; $+E B L$, estimated blood loss; $\neq$ LOS, length of hospital stay.

Table 3 shows the 8 SF-36 scale scores for patients in the preoperative and postoperative evaluation either in younger group (YG) and elderly group (EG) patients. A significant improvement in 4 of 8 scale score between the preoperative and postoperative evaluation both in the younger and elderly group has been observed. Comparisons of the preoperative and postoperative SF 36 summary scores in the two age groups were made.

There was no significant difference between the two age groups regarding PCS ( $45.6 \pm 7.8$ in YG vs. $44.2 \pm$ 8.2 in EG; $P=0.51)$ and MCS ( $48.1 \pm 10.7$ in YG vs. $46.9 \pm 9.2$ in $\mathrm{EG} ; \mathrm{P}=0.67$ ).

Similar results were also revealed in a comparison of the postoperative SF 36 summary scores. The postoperative PCS was $49.8 \pm 11.9$ in YG and $48.2 \pm 9.5$ in EG $(P=0.61)$. The postoperative MCS was also comparable between the two groups $(48.4 \pm 10.7$ in YG vs. $50.1 \pm$ 6.9 in EG; $P=0.54$ ).

\section{Discussion}

Surgical treatment in the so called "elderly" patients has been extensively reported even for oncological diseases either by laparotomy or laparoscopy [28,29].

Several studies showed laparoscopic surgery to be a safe and effective treatment for GERD being able to improve quality of life and warranting an early return to daily activities [30,31].

In elderly population with GERD, laparoscopic surgery has proven to be effective with low morbidity and mortality rates [32].

Previous study have shown comparable similar surgical results between the elderly group and nonelderly group including similar operation time, postoperative hospital stay, and low morbidity and mortality [33,34]. Our study also demonstrated similar results in terms of postoperative complication rate. The finding that younger patients had shorter hospitalization and operative times is in contrast with a recent report that compared elderly to younger patients undergoing laparoscopic antireflux surgery [35].

Though we did not look specifically at costs, longer operative times and length of hospital stay presumably might have affected operative and hospital expenses. In the current climate of medical cost control and limited resources, even the importance of cost-effectiveness 
Table 3 Comparison of the preoperative and postoperative SF-36 scale scores

\begin{tabular}{lllll}
\hline SF-36 scales & EG $(\mathbf{n}=\mathbf{1 6})$ preop & YG(n = 98)preop & EG (n= 16) postop & YG(n= 98)postop. \\
\hline Physical function & $65.5(18.4) \dagger$ & $73.3(19.2) \neq$ & $78.3(16.0)$ & $85.1(22.6)$ \\
Role limitations-physical & $56.4(21.6) \dagger$ & $59.4(22.9) \neq$ & $79.4(18.7)$ & $82.9(26.9)$ \\
Bodily pain & $52.5(19.3) \dagger$ & $55.5(19.1) \neq$ & $65.6(14.1)$ & $67.9(27.8)$ \\
General health perception & $60.2(23.4)$ & $62.1(21.2)$ & $62.8(18.3)$ & $65.5(18.2)$ \\
Vitality & $46.2(15.3) \dagger$ & $48.7(15.9) \neq$ & $58.6(17.5)$ & $61.5(20.9)$ \\
Social function & $69.4(18.1)$ & $71.2(19.9)$ & $71.0(12.5)$ & $74.6(21.9)$ \\
Role limitations-emotional & $66.8(19.9)$ & $69.4(20.6)$ & $75.1(16.0)$ & $73.1(34.5)$ \\
Mental health & $60.1(16.1)$ & $67.1(16.7)$ & $62.4(15.8)$ & $65.3(19.4)$ \\
\hline
\end{tabular}

All data reported as mean (SD).

preop $=$ preoperative; postop $=$ postoperativeHC $\_$healthy controls

*All preoperative an postoperative values were similar between EG and YG $(P=N S)$.

$t p<.05$, preoperative vs postoperative in EG group (mean follow-up period, $48.1 \pm 12.4 \mathrm{mo}$ ).

$\neq p<.05$, preoperative vs postoperative in EG group (mean follow-up period, $48.1 \pm 12.4 \mathrm{mo}$ ).

cannot be ignored when evaluating a surgical technique or procedure [36,37].

A significant postoperative improvement in heartburn, regurgitation, chest pain and respiratory complications of GERD was observed in both EG and YG.

An excellent outcome after treatment was observed in a very high percentage of patients in both groups. A poor outcome was observed in those with a persistent postoperative dysphagia

A previous study showed laparoscopic total fundoplication is a safe and effective surgical treatment for gastroesophageal reflux disease generally offering an improved long-term quality of life, with the exception of a minority of patients who experience persistent severe dysphagia [38]. Authors suggested these patients may be offered the opportunity to undergo a laparoscopic redo fundoplication to treat the residual symptom, with encouraging results.

The current study employed the SF-36 as a well-validated and reliable health status measure widely used in medical and health services assessing the generic (ie, not diseasespecific) quality of life. In particular, patients in both groups improved in 3 scale scores that represent physical health: these measured physical function, rolelimitation physical, and bodily pain and also in a scale score that normally is classified as a measure of mental health: vitality (energy and fatigue). In addition, the other 4 scale scores improved after laparoscopic total fundoplication without reaching statistical significance. There were also no significant difference in postoperative PCS and MCS scores based on the SF-36 between younger and elderly at long term follow up.

At last, we found overall outcome for patients who underwent surgery primarily for reflux was very good, with a very high satisfaction rate resulting comparable between younger and elderly

This finding is in keeping with previous studies stressing age should not be considered a contraindication to laparoscopic antireflux surgery that is a good option for the treatment of severe GERD also in octo- and nonagenarians [39]. The present study is potentially limited by the exclusive use of a general measure of health status. The additional use of a disease specific quality of life instrument has been recommended by the European Study Group for Antireflux Surgery [40,41]. This is important, especially if research's object is to adequately focus on an area of interest such as severity of symptoms as well as on response to treatment [42-44]. At last, this is a single tertiary referral center study and does not allow determination of the long-term outcome in a community practice setting.

In conclusion, laparoscopic total fundoplication is a safe and effective surgical treatment for gastroesophageal reflux disease generally warranting low morbidity and mortality rates and a significant improvement of symptoms comparable. An improved long-term quality of life is warranted even in the elderly.

\section{List of abbreviations used}

Gastro-Esophageal Reflux Disease (GERD); Elderly Group (EG); Young Group (YG); Quality of life (QOL); Physical Component Summary (PCS); Mental Component Summary (MCS)

\section{Competing interests}

The authors declare that they have no competing interests.

\section{Authors' contributions}

ST, GDG, GD have made substantial contributions to conception and design; LB, IV, SG have made substantial contributions to acquisition of data; CV, ADA, GC have made substantial contributions to analysis and interpretation of data; FSL, NL, RP have been involved in drafting the manuscript; LD, GD, RR have been involved in revising it critically for important intellectual content; ST, GD, RR have given final approval of the version to be published.

\section{Authors' information}

ST Research Grant Fellow at Second University of Naples; GD Associate Professor of Surgery at Second University of Naples; GDG Assistant Professor of Surgery at Second University of Naples; LB Senior Doctor at Second University of Naples; IV Senior Doctor at Second University of Naples; SG Research Fellow at Second University of Naples; CV Medical Student at Second University of Naples; ADA Surgical Fellow Resident at Second 
University of Naples; GC Surgical Fellow Resident at Second University of Naples; FSL Medical Doctor at Second University of Naples; NL Medical Student at Second University of Naples; RP Medical Student at Second University of Naples; RR Assistant Professor of Surgery at Second University of Naples; LD Full Professor of Surgery at Second University of Naples.

\section{Declarations}

Funding for this article has come from personal funds.

This article has been published as part of BMC Surgery Volume 13 Supplement 2, 2013: Proceedings from the 26th National Congress of the Italian Society of Geriatric Surgery. The full contents of the supplement are available online at http://www.biomedcentral.com/bmcsurg/supplements/13/ S2

Published: 8 October 2013

\section{References}

1. Spechler SJ: Disease of the esophageal mucosa. In Disease of the Gastrointestinal Tract and the Liver. Edinburgh: Churchill-Livingstone; Shearman DJC, Finlayson NC, Camilleri M 1997:191-216.

2. Lundell L, Miettinen P, Myrvold HE, Hatlebakk JG, Wallin L, Engström C, Julkunen R, Montgomery M, Malm A, Lind T, Walan A, Nordic GERD Study Group: Comparison of outcomes twelve years after antireflux surgery or omeprazole maintenance therapy for reflux esophagitis. Clin Gastroenterol Hepatol 2009, 12:1292-8.

3. Belli G, Fantini C, D'Agostino A, Cioffi L, Russo G, Belli A, Limongelli P. Single port laparoscopic cholecystectomy: a new evolving technique. Hepatogastroenterology 2011, 58(109):1132-6.

4. Conzo G, Amato G, Angrisani L, Bardi U, Belli G, Brancaccio U, Calise F, Celsi S, Corcione F, Cuccurullo D, De Falco G, De Werra C, De Sena G, Docimo G, Esposito MG, Fantini C, Giardiello C, Livrea A, Lorenzo M, Molino C, Musella M, Muto C, Palazzo A, Porcelli A, Rea R, Rendano F, Santangelo M, Santaniello W, Santini L, Sperlongano P, Stanzione F, Tartaglia A, Tricarico A, Vincenti R, Delrio P: Hepaticojejunostomy in the treatment of iatrogenic biliary lesions following laparoscopic cholecystectomy. A retrospective study on 51 cases. Hepatogastroenterology 2007, 54(80):2328-32.

5. Conzo G, Amato G, Angrisani L, Bardi U, Barone G, Belli G, Brancaccio U, Calise F, Caliendo A, Celsi S, Corcione F, Cuccurullo D, De Falco G, Delrio P, De Werra C, De Sena G, Docimo G, Esposito MG, Fantini C, Giardiello C, Musella M, Molino C, Muto C, Pennetti L, Puziello A, Porcelli A, Rea R, Rendano F, Palazzo A, Santangelo M, Santaniello W, Santini L, Sperlongano P, Stanzione F, Tartaglia A, Tricarico A, Vincenti R, Lorenzo M: Surgical treatment of iatrogenic bile duct injuries following laparoscopic cholecystectomy: analysis of long-term results. Retrospective clinical study in 51 patients operated in the Campania region from 1991 to 2003. Chir Ital 2005, 57(4):417-24.

6. Docimo G, Manzi F, Maione L, Canero A, Veneto F, Lo Schiavo F, Sparavigna L, Amoroso V, De Rosa M, Docimo L: Case report: laparoscopic cholecystectomy in situs viscerum inversus. Hepatogastroenterology 2004, 51(58):958-60.

7. Belli G, Cioffi L, D'Agostino A, Limongelli P, Belli A, Russo G, Fantini C: Revision surgery for incidentally detected early gallbladder cancer in laparoscopic era. J Laparoendosc Adv Surg Tech A 2011, 21(6):531-4.

8. Agresta F, De Simone P, Leone L, Arezzo A, Biondi A, Bottero L, Catena F, Conzo G, Del Genio, Guerrieri M, Illomei G, Tonelli P, Vitellaro M, Docimo G, Crucitti A: Laparoscopic Appendectomy in Italy: An Appraisal of 26,863 Cases. Journal of Laparoendoscopic and Advanced Surgical Techniques - Part A 2004, 14:1, 1-8 February.

9. Parmeggiani D, Cimmino G, Cerbone D, Avenia N, Ruggero R, Gubitosi A, Docimo G, Mordente S, Misso C, Parmeggiani U: Biliary tract injuries during laparoscopic cholecystectomy: three case reports and literature review. ( Review ). G Chir 2010, 31(1-2):16-9, Jan-Feb.

10. Belli G, Cioffi L, Fantini C, D'Agostino A, Russo G, Limongelli P, Belli A: Laparoscopic redo surgery for recurrent hepatocellular carcinoma in cirrhotic patients: feasibility, safety, and results. Surg Endosc 2009, 23(8):1807-11, Aug

11. Belli G, Fantini C, D'Agostino A, Cioffi L, Limongelli P, Russo G, Belli A: Laparoscopic segment VI liver resection using a left lateral decubitus position: a personal modified technique. J Gastrointest Surg 2008, 12(12):2221, Dec.
12. del Genio G, Rossetti G, Brusciano L, Limongelli P, Pizza F, Tolone S, Fei L, Maffettone V, Napolitano V, del Genio A: Laparoscopic Nissen-Rossetti fundoplication with routine use of intraoperative endoscopy and manometry: technical aspects of a standardized technique. World I Surg 2007, 31(5):1099-106, May.

13. lovino $P$, Pascariello A, Limongelli $P$, Tremolaterra F, Consalvo D, Sabbatini F, Amato G, Ciacci C: The prevalence of sexual behavior disorders in patients with treated and untreated gastroesophageal reflux disease. Surg Endosc 2007, 21(7):1104-10, Jul.

14. Pizza F, Rossetti G, Limongelli P, Del Genio G, Maffettone V, Napolitano V, Brusciano L, Russo G, Tolone S, Di Martino M, Del Genio A: Influence of age on outcome of total laparoscopic fundoplication for gastroesophageal reflux disease. World J Gastroenterol 2007, 13(5):740-7, Feb 7.

15. Grotenhuis BA, Wijnhoven BP, Bessell JR, Watson DI: Laparoscopic antireflux surgery in the elderly. Surg Endosc 2008, 22:1807-1812

16. Tolone S, Del Genio G, Docimo G, Brusciano L, del Genio A, Docimo L: Objective outcomes of extra-esophageal symptoms following laparoscopic total fundoplication by means of combined multichannel intraluminal impedance $\mathrm{pH}$-metry before and after surgery. Updates Surg 2012, 64(4):265-71, Dec.

17. Ware JE Jr, Snow KK, Kosinski M, et al: SF-36 Health Survey: Manual and Interpretation Guide. Boston: The Health Institute, New England Medical Center; 1993.

18. Apolone G, Mosconi P: The Italian SF-36 health survey: translation, validation and norming. J Clin Epidemiol 1998, 51:1025-36.

19. Avenia N, Sanguinetti A, Cirocchi R, Docimo G, Ragusa M, Ruggiero R, Procaccini E, Boselli C, D'Ajello F, Parmeggiani D, Rosato L, Sciannameo F, De Toma G, Noya G: Antibiotic prophylaxis in thyroid surgery: A preliminary multicentric italian experience Annals of Surgical. Ann Surg Innov Res 2009, 3:10, Aug 5, doi: 10.1186/1750-1164-3-10.

20. Ruggiero R, Sparavigna L, Gubitosi A, Agresti M, Procaccini E, Docimo L: Post-operative peritonitis due to anastomotic dehiscence after colonic resection. Multicentric experience, retrospective analysis of risk factors and review of the literature ( Review ). Ann Ital Chir 2011, 82(5):369-75, Sep-Oct.

21. Sanguinetti A, Docimo G, Ragusa M, Calzolari F, D'Ajello F, Ruggiero R, Parmeggiani D, Pezzolla A, Procaccini E, Avenia N: Ultrasound scissors versus electrocautery in axillary dissection: our experience. G Chir 2010, 31(4):151-3, Apr.

22. D'Ajello F, Cirocchi R, Docimo G, Catania A, Ardito G, Rosato L, Avenia N: Thyroidectomy with ultrasonic dissector: a multicentric experience. $G$ Chir 2010, 31(6-7):289-92, Jun-Jul.

23. Docimo G, Ruggiero R, Gubitosi A, Casalino G, Bosco A, Gili S, Conzo G, Docimo L: Ultrasound scalpel in thyroidectomy: Prospective randomized study. Ann Ital Chir 2012, 83(6):491-6, Nov-Dec.

24. Ruggiero R, Procaccini E, Piazza P, Docimo G, lovino F, Antonioli G, Irlandese E, Gili S, Lo Schiavo F: Effectiveness of fibrin glue in conjunction with collagen patches to reduce seroma formation after axillary lymphadenectomy for breast cancer. Am J Surg 2008, 196(2):170-4, Aug.

25. Marfella R, Barbieri M, Ruggiero R, Rizzo MR, Grella R, Mozzillo AL, Docimo L, Paolisso G: Bariatric surgery reduces oxidative stress by blunting 24-h acute glucose fluctuations in type 2 diabetic obese patients. Diabetes Care 2010, 33(2):287-9, Feb.

26. Marfella R, Luongo C, Coppola A, Luongo M, Capodanno P, Ruggiero R, Mascolo L, Ambrosino I, Sardu C, Boccardi V, Lettieri B, Paolisso G: Use of a non-specific immunomodulation therapy as a therapeutic vasculogenesis strategy in no-option critical limb ischemia patients. Atherosclerosis 2010, 208(2):473-9, Feb.

27. Selvaggi F, Sciaudone G, Limongelli P, Di Stazio C, Guadagni I, Pellino G, De Rosa M, Riegler $\mathrm{G}$ : The effect of pelvic septic complications on function and quality of life after ileal pouch-anal anastomosis: a single center experience. Am Surg 2010, 76(4):428-35, Apr.

28. Sommerville CA, Limongelli P, Pai M, Ahmad R, Stamp G, Habib NA, Williamson RC, Jiao LR: Survival analysis after pancreatic resection for ampullary and pancreatic head carcinoma: an analysis of clinicopathological factors. J Surg Oncol 2009, 100(8):651-6, Dec 15

29. Spampinato MG, Arvanitakis M, Puleo F, Mandala L, Quarta G, Traisci D, Plaia A, Bartolomeo ND, Baldazzi G, Cillo U: Totally laparoscopic liver resections for primary and metastatic cancer in the elderly: safety, feasibility and short-term outcomes. Surg Endosc 2012, Dec 8. 
30. Hinder RA, Filipi CJ, Wetscher G, Neary P, DeMeester TR, Perdikis G: Laparoscopic Nissen fundoplication is an effective treatment for gastroesophageal reflux disease. Ann Surg 1994, 220:472-481, discussion 481-483.

31. Trus TL, Laycock WS, Waring JP, Branum GD, Hunter JG: Improvement in quality of life measures after laparoscopic antireflux surgery. Ann Surg 1999, 229(3):331-6, Mar.

32. Compagna R, Rispoli C, Rocco N, Braun A, Avallone U, Amato B: Laparoscopic antireflux surgery in the elderly. BMC Geriatrics 2009, 9(SUPPL. 1):A29.

33. Kamolz T, Bammer T, Granderath FA, Pasiut M, Pointner R: Quality of life and surgical outcome after laparoscopic antireflux surgery in the elderly gastroesophageal refl ux disease patient. Scand J Gastroenterol 2001, 2:116-20.

34. Kamolz T, Granderath FA, Bammer T, Pasiut M, Pointner P: Failed antireflux surgery: surgical outcome of laparoscopic refundoplication in the elderly. Hepato-Gastroenterology 2002, 49:865-8.

35. Wang $W$, Huang MT, Wei PL, Lee WJ: Laparoscopic antireflux surgery for the elderly: a surgical and quality-of-life study. Surg Today 2008, 38(4):305-10.

36. Limongelli P, Belli A, Russo G, Cioffi L, D’Agostino A, Fantini C, Belli G: Laparoscopic and open surgical treatment of left-sided pancreatic lesions: clinical outcomes and cost-effectiveness analysis. Surg Endosc 2012, 26(7):1830-6, Jul.

37. Grant A, Wileman S, Ramsay C, Bojke L, Epstein D, Sculpher M, Macran S, Kilonzo M, Vale L, Francis J, Mowat A, Krukowski Z, Heading R, Thursz M, Russell I, Campbell M: REFLUX Trial Group.The effectiveness and costeffectiveness of minimal access surgery amongst people with gastrooesophageal reflux disease - a UK collaborative study. The REFLUX trial. Health Technol Assess 2008, 12(31):1-181, Sep.

38. Amato G, Limongelli P, Pascariello A, Rossetti G, Del Genio G, Del Genio A, lovino P: Association between persistent symptoms and long-term quality of life after laparoscopic total fundoplication. Am J Surg 2008, 196(4):582-6, Oct.

39. Bammer T, Hinder RA, Klaus A, Libbey JS, Napoliello DA, Rodriquez JA: Safety and long-term outcome of laparoscopic antirefl ux surgery in patients in their eighties and older. Surg Endosc 2002, 16:40-42.

40. Korolija D, Sauerland S, Wood-Dauphinée S, Abbou CC, Eypasch E, Caballero MG, Lumsden MA, Millat B, Monson JR, Nilsson G, Pointner R, Schwenk W, Shamiyeh A, Szold A, Targarona E, Ure B, Neugebauer E, European Association for Endoscopic Surgery: Evaluation of quality of life after laparoscopic surgery: evidence-based guidelines of the European Association for Endoscopic Surgery. Surg Endosc 2004, 18(6):879-97, Jun.

41. Compagna R, Rispoli C, Rocco N, Braun A, Avallone U, Amato B: Laparoscopic antireflux surgery in the elderly. BMC Geriatrics 2009 9(SUPPL. 1), Article numberA29.

42. del Genio G, Tolone S, Rossetti G, Brusciano L, Pizza F, del Genio F, Russo F, Di Martino M, Lucido F, Barra L, Maffettone V, Napolitano V, del Genio A: Objective assessment of gastroesophageal reflux after extended Heller myotomy and total fundoplication for achalasia with the use of 24-hour combined multichannel intraluminal impedance and $\mathrm{pH}$ monitoring (MII-pH). Dis Esophagus 2008, 21(7):664-7.

43. Rispoli C, Rocco N, lannone L, Compagna R, Cacciapuoti MT, Bellino A, Amato B: Breast reconstruction in older women: $\mathrm{A}$ growing request. $B M C$ Geriatrics 2009, 9(SUPPL. 1), Article numberA46.

44. del Genio G, Tolone S, del Genio F, d'Alessandro A, Brusciano L, Conso G, Aggarwal R, Docimo L, del Genio A: Impact of total fundoplication on esophageal transit. Analysis by combined multichannel intraluminal impedance and manometry. J Clin Gastroenterol 2012, 46(1):e1-5.

doi:10.1186/1471-2482-13-S2-S10

Cite this article as: Tolone et al:: Long term quality of life after laparoscopic antireflux surgery for the elderly. BMC Surgery 2013 13(Suppl 2):S10.

\section{Submit your next manuscript to BioMed Central and take full advantage of:}

- Convenient online submission

- Thorough peer review

- No space constraints or color figure charges

- Immediate publication on acceptance

- Inclusion in PubMed, CAS, Scopus and Google Scholar

- Research which is freely available for redistribution

Submit your manuscript at www.biomedcentral.com/submit
Biomed Central 